\title{
Connectivity and bottlenecks in a migratory wildebeest Connochaetes taurinus population
}

\author{
Thomas A. Morrison and Douglas T. Bolger
}

\begin{abstract}
Surprisingly little is known about the spatial dimensions of most tropical ungulate migrations, including that of wildebeest Connochaetes taurinus, a species famous for long-distance movements. Using non-invasive photographic identification of 834 adult wildebeest from 8,530 images collected over 4 years we characterize patterns of migratory connectivity throughout the northern TarangireManyara Ecosystem, Tanzania. We document movements between Tarangire and Lake Manyara National Parks and northwards to the shore of Lake Natron, a straightline distance of $>130 \mathrm{~km}$. Fifty-six percent of observed movements occur outside the ecosystem's three main protected areas. We supplement photographic data with fine-scale movement data from two individuals with global positioning system collars, and identify three narrow bottlenecks, each vulnerable to human development. We discuss the possible consequences for the wildebeest population if these bottlenecks become impeded. Persistence of this migration alongside a growing human population and proposed road improvement will require additional measures to ensure that pathways remain open to wildlife movement and protected from illegal hunting.
\end{abstract}

Keywords Barriers, connectivity, Connochaetes taurinus, Lake Natron, migration, Tarangire, ungulate, wildebeest

\section{Introduction}

$\mathrm{M}$ aintaining connectivity in terrestrial ecosystems is a basic, but challenging, conservation goal (Crooks \& Sanjayan, 2006). For migratory wildlife, habitat fragmentation and barriers along a migration route are increasingly causing loss of connectivity and preventing animals from accessing seasonal ranges (Sawyer et al., 2013), often resulting in population declines or local extirpations (Bolger et al., 2008; Harris et al., 2009; Fynn \& Bonyongo, 2010). Migratory ungulates play prominent roles in landscape-scale conservation because of their large area requirements (Thirgood et al., 2004), their importance as drivers of ecological structure and function (e.g. Holdo et al., 2009) and their

ThOmas A. MoRrison (Corresponding author) Wyoming Cooperative Fish and Wildlife Research Unit, Department of Zoology and Physiology, University of Wyoming, Laramie, WY 82071, USA. E-mail tmorrison80@gmail.com

Douglas T. Bolger Environmental Studies Program, Dartmouth College, Hanover, New Hampshire, USA

Received 12 September 2012. Revision requested 14 January 2013.

Accepted 5 March 2013. First published online 13 March 2014. ability to attract public attention and funding. Ungulate migration is generally considered an adaptive strategy that provides prolonged access to high-quality forage, while reducing exposure to predation (Fryxell \& Sinclair, 1988; Hebblewhite \& Merrill, 2007). In tropical ecosystems ungulates migrate across gradients in plant nutrient concentrations, such as nitrogen, calcium and phosphorus (McNaughton, 1990) which vary inversely with annual rainfall (Hopcraft et al., 2010). Thus, a loss of connectivity in these systems presumably eliminates the ecological benefits derived from migration (Bolger et al., 2008).

Arguably, the most critical areas for maintaining connectivity in migratory landscapes are bottlenecks, or places along the migration route where movement is restricted on multiple sides by impermeable physical barriers such as steep topography, rivers, anthropogenic development or unsuitable habitat (Berger et al., 2006). Bottlenecks have high conservation value because relatively small changes in land-use in these areas can prevent migratory wildlife from accessing much larger portions of their ranges. However, identifying bottlenecks is challenging because it requires assumptions about an animal's tolerance, or avoidance, of particular types of topography or habitat, including areas of anthropogenic development (Sawyer et al., 2013). Although movement data from global positioning systems (GPS) may indicate that migration routes become narrow in certain areas, one cannot rule out the existence of alternative unobserved or unused routes (Sawyer et al., 2009). Previous studies have taken a practical approach to this issue: movement data are integrated with knowledge of species ecology to infer locations where movements are most likely constrained (e.g. Berger et al., 2006).

Here, we use photographic identification of individual wildebeest Connochaetes taurinus as a novel means of characterizing migratory connectivity for a population of wildebeest. This photo ID methodology provides a rigorous way to follow the coarse-scale movements of large numbers of individuals across their annual migratory cycle (Morrison \& Bolger, 2012). We supplement these results with GPScollar data to help confirm the patterns of connectivity. We highlight areas that appear particularly vulnerable because of existing bottlenecks that lie near expanding or proposed anthropogenic development.

\section{Study area}

The c. $20,000 \mathrm{~km}^{2}$ Tarangire-Manyara Ecosystem is a savannah ecosystem in the eastern branch of the Rift Valley 

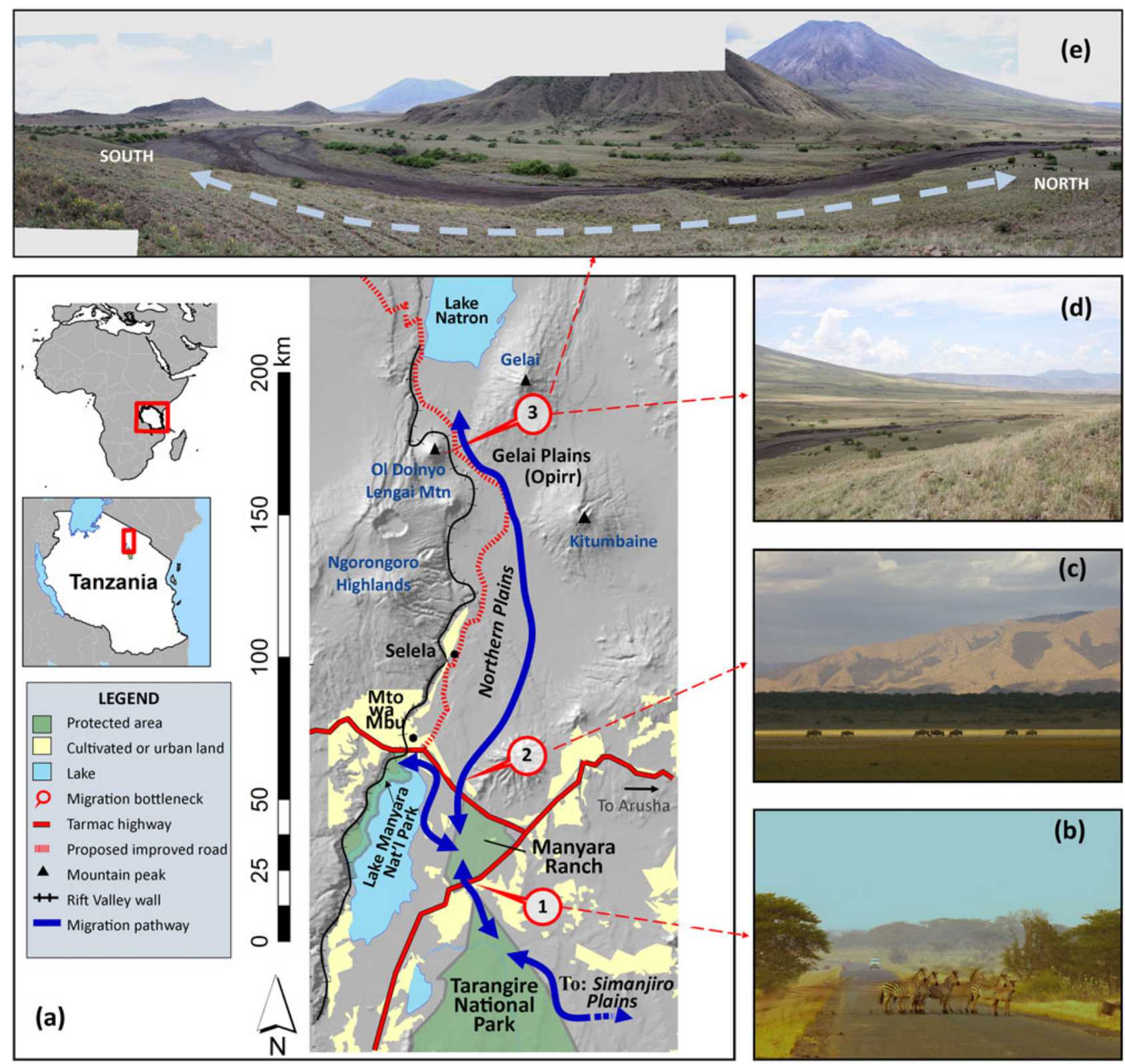

Fig. 1 (a) The Northern Plains of the Tarangire-Manyara Ecosystem, Tanzania. The migration path passes three narrow bottlenecks: Kwakuchinja (1 on map, and (b)), Esilalei (2 on map, and (c)) and Ol Doinyo Lengai (3 on map, and (d) and (e)). In (e) Ol Doinyo Lengai mountain is in the background.

in northern Tanzania (Fig. 1; Borner, 1985). Land in the ecosystem is managed for a variety of uses (Table 1). The ecosystem contains three main protected areas: Tarangire $\left(2,600 \mathrm{~km}^{2}\right)$ and Lake Manyara $\left(317 \mathrm{~km}^{2}\right)$ National Parks, which are managed for wildlife tourism, and Manyara Ranch $\left(177 \mathrm{~km}^{2}\right)$, a private land conservancy that prohibits hunting and farming, and restricts livestock grazing and tourism to relatively low levels. The majority of remaining rangeland is managed as open areas or game controlled areas, on which livestock grazing, agricultural cultivation, settlement, game hunting and tourism are permitted. These areas generally lack consistent anti-poaching enforcement; thus, illegal hunting of wildlife is a major conservation issue throughout the ecosystem (Sachedina, 2008; Estes \& East, 2009).

When first described by biologists, the greater TarangireManyara Ecosystem was a seasonal dispersal system: large numbers of wildebeest, zebra Equus quagga and other large mammals congregated in Tarangire and Lake Manyara National Parks during the dry season (July-October) and dispersed outside the parks in at least five directions during the wet season (November-June; Lamprey, 1964). In recent decades agricultural intensification and new settlements have channelled movements in two main directions (Borner, 1985; Morrison \& Bolger, 2012): the Simanjiro Plains and the Northern Plains (Fig. 1). The loss of dispersal 


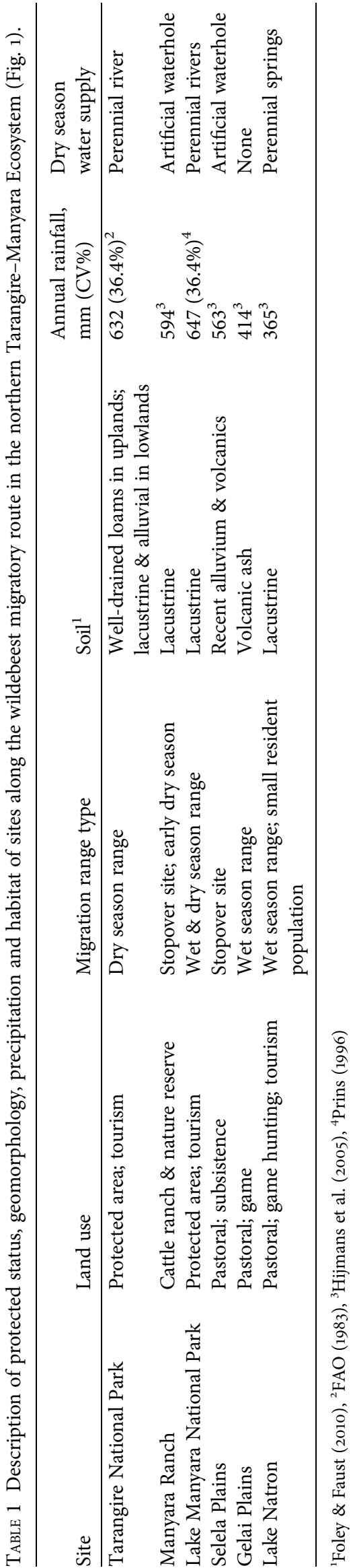

routes has coincided with dramatic population declines in migratory ungulates: between 1988 and 2001 (the most recent aerial census), abundance of wildebeest declined by c. $90 \%$ (TAWIRI, 2001). Of the two remaining wet season ranges the Simanjiro Plains have received the majority of scientific and conservation attention, largely because of rapid and conspicuous loss of habitat following the conversion of rangeland to agriculture (TCP, 1998; Voeten et al., 2010).

Until recently, north-south migratory movements in the ecosystem had been poorly documented (Morrison \& Bolger, 2012; but see TCP, 1998). Approximately 50\% of the migratory wildebeest population from Tarangire National Park, several thousand adults, migrated along the Northern Plains during 2006-2007, with the remaining animals moving to the Simanjiro Plains (Morrison et al., unpubl. data.; Fig. 1). Several hundred wildebeest also remain yearround in Lake Manyara National Park (Prins \& DouglasHamilton, 1990; Morrison \& Bolger, 2012). The Gregory Rift wall (500-1,000 $\mathrm{m}$ in height) to the west of the ecosystem forms a barrier to gene flow between the TarangireManyara and Serengeti wildebeest populations (Georgiadis, 1995). On the eastern side of the valley there is a chain of forested mountains (Fig. 1) and shrub-dominated habitat that impedes (though may not entirely preclude) passage to grasslands in Amboseli and West Kilimanjaro. Immediately north of Lake Natron in Kenya is Shampole Group Ranch, which supports several hundred resident wildebeest (Estes \& East, 2009).

\section{Methods}

Photographic capture-recapture surveys

Wildebeest were photographed on six occasions between May 2005 and February 2009 (May-July 2005, May-August 2006, October-December 2006, May-July 2007, OctoberNovember 2007 and January-February 2009), corresponding approximately to the end of the wet season (May-June) and end of the dry season (October-November). Images were collected in six sampling areas: Tarangire and Lake Manyara National Parks, Manyara Ranch, Selela village, the Gelai Plains (known locally as Opirr) and the shore of Lake Natron (Fig. 1). The final sampling period (2009) was the only occasion to include Lake Natron as a sampling area; prior to 2009 we had not observed or been aware of wildebeest migrating in large numbers to this area. At the beginning of each survey we drove the main roads of the ecosystem and spoke to local informants to determine the locations of wildebeest aggregations. We approached herds from a vehicle and photographed the right-side flanks of animals as they stood perpendicular to the vehicle, typically at a distance of $10-100 \mathrm{~m}$, using a window-mounted 6.1 

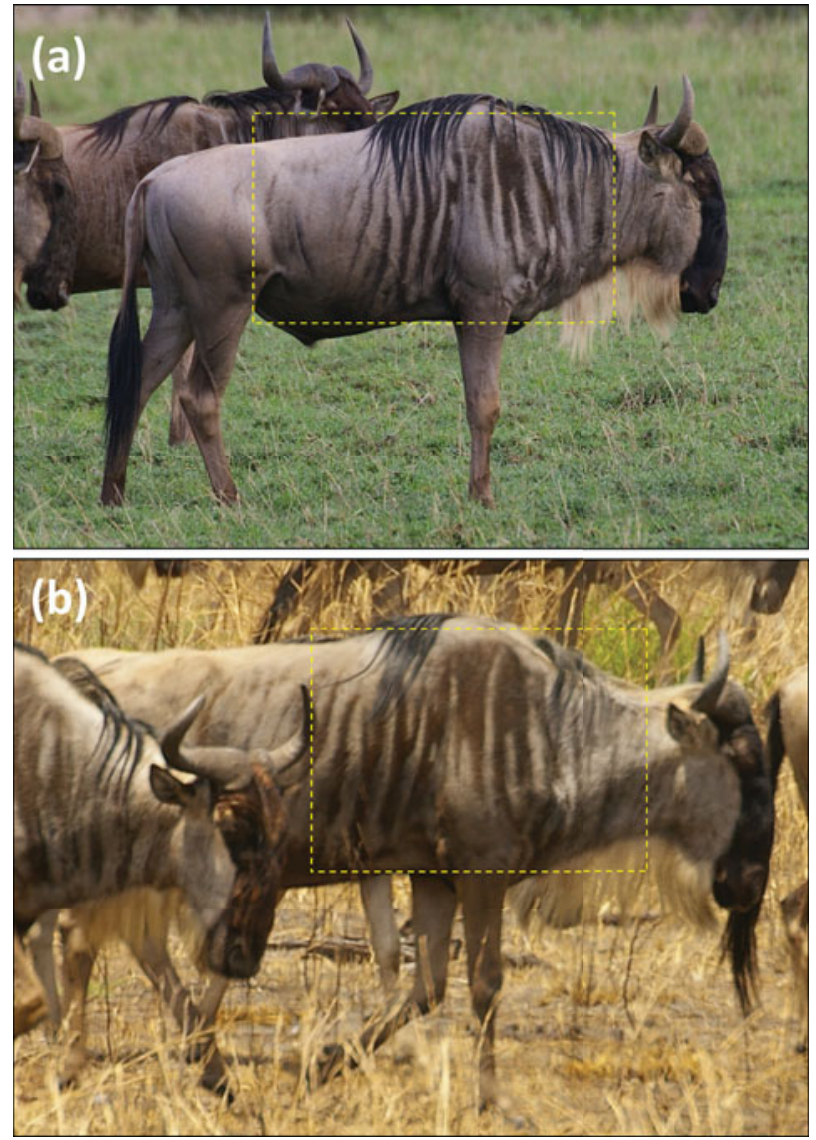

Plate 1 Example of an adult wildebeest captured on two occasions (December 2006 in the Gelai Plains (a) and October 2007 in Tarangire National Park (b)), showing stripe patterns and cropped area (dotted rectangle) used for individual identification.

megapixel camera with a 400-mm telephoto zoom lens. Only adults ( $>_{1}$ year old) were photographed; younger individuals could not be reliably identified because of indistinct stripe patterns. For each herd we attempted to collect as many photographs as there were adults. Herds were defined as aggregations in which no individual was $>100 \mathrm{~m}$ away from the next closest individual (Morrison \& Bolger, 2012). We aimed to photograph $40-50 \%$ of all adults within each sampling area to balance sample size and coverage. Actual capture rates (i.e. the percentage of adults identified) were much lower because many individuals were unknowingly photographed multiple times, whereas others were missed, and c. $30 \%$ of images were too poor in quality to be used for matching (Morrison \& Bolger, 2012).

\section{Individual identification}

Wildebeest were identified from photographs by their shoulder stripe patterns, which are unique to each individual (Plate 1; Morrison et al., 2011). Low-quality images, largely a combination of poor image resolution, poor focus and individuals containing little pattern variation, were discarded. Remaining high-quality images were cropped to the shoulder region of the animal (Plate 1). Obstructions in photos (e.g. other animals, vegetation) were also cropped. We used Wild-ID (2013) to assist in the identification of individuals (see Bolger et al., 2012 for full details of the methodology). Image matches were found by visually comparing each new image in the database to the top 20 most similar candidate matches, based on Wild-ID similarity scores. Sexes were separated during image comparisons.

Capture histories were compiled for all individuals, with recaptures defined as any set of photos of the same individual taken on different days. Our data were not well suited for capture-recapture models nor were our hypotheses testable through these methods (see Morrison \& Bolger (2012) for a seasonal multistate capture-recapture model in this ecosystem that includes the Simanjiro Plains). Our main goal was simply to document connectivity (a binary response variable) between sampling areas and to establish whether animals near Lake Natron originated from Tarangire and Lake Manyara National Parks. False rejection errors in the image matching process (i.e. failing to match two photographs of the same individual) would not have prevented observing connectivity between two areas and were thus not of concern. False acceptance errors (incorrectly matching two images of different individuals), however, could potentially bias conclusions. Morrison \& Bolger (2012) estimated the probability of this error type as $<0.001$ based on a test set of 100 images of 50 individuals that could be identified independently of their stripe patterns. Therefore, we were confident that a high proportion of observed matching-image pairs (i.e. recaptures) represented the same individual.

We measured the total distance between consecutive captures inside and outside the three main protected areas (Tarangire and Lake Manyara National Parks and Manyara Ranch) by drawing straight-line segments between GPS locations of capture sites of each individual to calculate a total movement length and then clipping line segments that fell outside the three protected areas, using ArcGIS v. 10.0 (ESRI, Redlands, USA).

\section{Identifying bottlenecks}

We summarized information on bottlenecks, using various sources: previous accounts of wildlife movements, unstructured interviews with local pastoralists, our own visits to the bottleneck areas, inspection of landscape features in satellite imagery, and locations of two GPS-collared wildebeest. The GPS collars (Telonics TGW-4780H) were deployed on 10 and 11 October 2011 in Manyara Ranch. Collared animals 

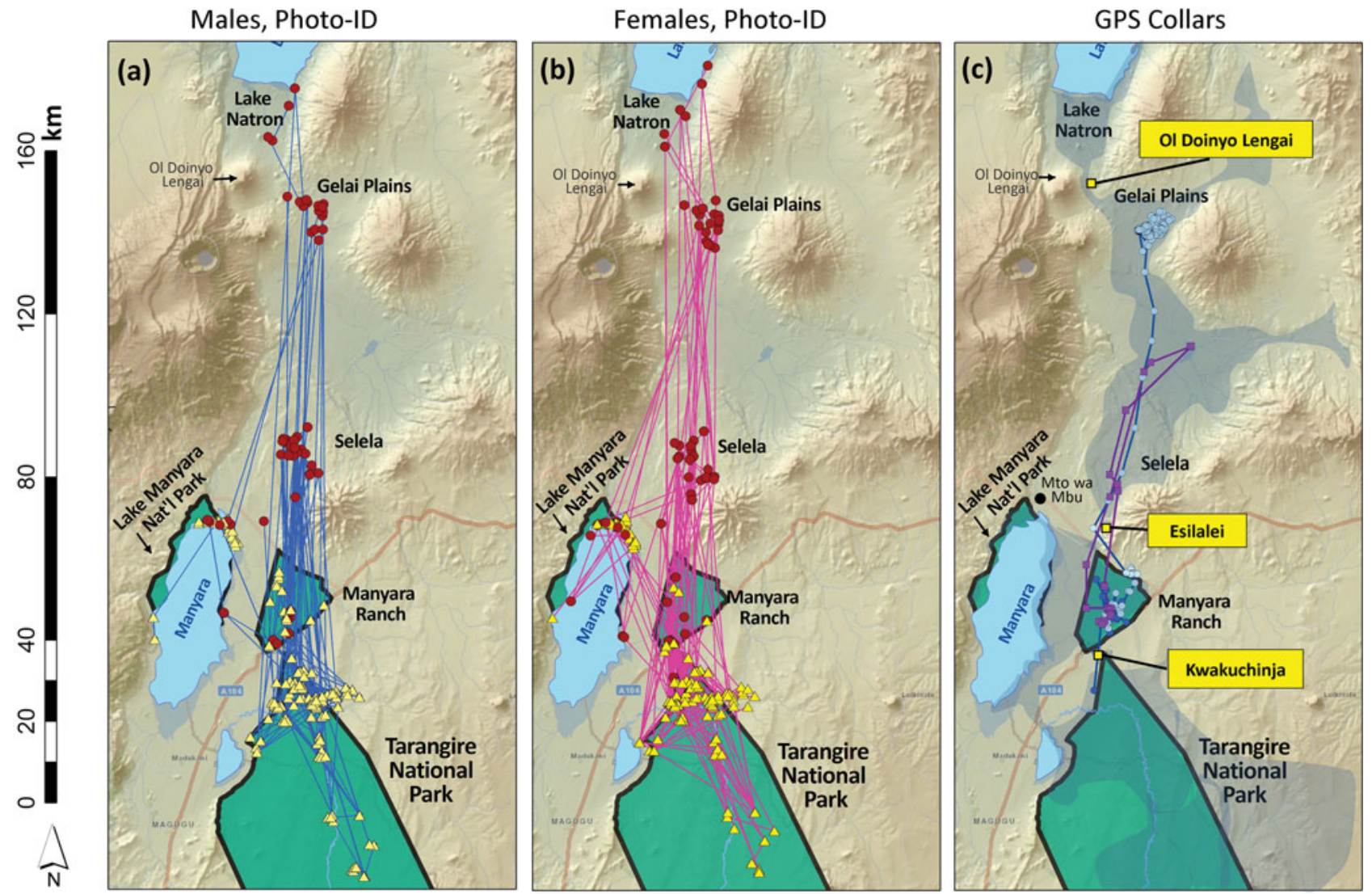

FIG. 2 Migratory connectivity within the northern portion of the Tarangire-Manyara Ecosystem. (a) Bull and (b) cow wildebeest from photographic capture-recapture (cf. Table 2): triangles indicate dry season photographic captures (July-November) and circles indicate wet season captures (December-June); lines connect consecutive captures of unique individuals. Connectivity patterns in (a) and

(b) reflect where and how intensively we sampled rather than providing an accurate measure of movement probability (see Methods).

(c) Movements based on GPS collar data for a cow (dark symbols) and bull (light symbols) wildebeest, with the approximate

wildebeest distribution (shaded polygon) and location of bottlenecks.

were immobilized with an injectable dart containing $6 \mathrm{mg}$ of etorphine and $80-100 \mathrm{mg}$ of azaperone, fired from a veterinary rifle from the ground. Individuals were GPScollared by a Tanzanian Wildlife Research Institute veterinarian following the protocols established by the Institute.

We defined bottlenecks as any area along a migration path where movement is probably constrained to $<5 \mathrm{~km}$ in width by steep topography or cultivated land and dense human settlements. We assumed wildebeest generally avoided rocky hillsides when migrating because these areas typically have loose soil or dense woody vegetation. As obligate grazers (Casebeer \& Koss, 1970) wildebeest would have poor forage in this habitat. We also assumed wildebeest avoided dense cultivated and settled areas (Ogutu et al., 2010). Most cultivated land in the study area is in small, rain-fed subsistence farms that lack fencing. Although movements through these farms and near human settlements are possible, especially at night, wildebeest are generally skittish near human settlements and do not cropraid (Goldman, 2003). These generalizations agree with our own extensive observations of wildebeest behaviour.

\section{Results}

\section{Migratory connectivity}

We collected 8,530 high-quality images of 5,682 individuals (3,390 females and 2,292 males). Of these individuals 834 were recaptured and most (83.9\%) of these were recaptured only once, although the maximum number of recaptures was 12 (a female observed exclusively in Lake Manyara National Park). The majority of recaptures occurred within the same sampling areas $(80.0 \%$ of female recaptures and $83.2 \%$ of males), with $44 \%$ of all recaptures occurring in Tarangire National Park. We observed movements among all six sampling areas in at least a few individuals (Fig. 2; Table 2; note that Table 2 shows only consecutive captures, i.e. time $i$ to $i+1)$.

Recaptures spanned the entire extent of the study area; individuals recaptured near Lake Natron were first observed in Lake Manyara National Park (one adult female), Tarangire National Park (two adult males), Manyara Ranch (two adult females), Selela (two adult females) and the Gelai Plains (two males, three females; Fig. 2). The 
TABLE 2 Number of photographic recaptures of wildebeest from time $i$ to time $i+1$ between Lake Natron (LN), Gelai Plains (GP), Selela (SEL), Lake Manyara National Park (LMNP), Manyara Ranch (MR) and Tarangire National Park (TNP). This table summarizes movements from Fig. 2a,b. The matrix only includes transitions between consecutive captures.

\begin{tabular}{lllrrrr}
\hline & \multicolumn{6}{l}{ Time $i+1$} \\
\cline { 2 - 7 } Time $i$ & LN & GP & SEL & LMNP & MR & TNP \\
\hline Cows & & & & & & \\
LN & 2 & 0 & 0 & 0 & 0 & 0 \\
GP & 4 & 8 & 2 & 1 & 0 & 3 \\
SEL & 3 & 5 & 28 & 0 & 7 & 20 \\
LMNP & 0 & 3 & 2 & 152 & 2 & 5 \\
MR & 2 & 0 & 4 & 1 & 53 & 43 \\
TNP & 0 & 0 & 7 & 3 & 13 & 277 \\
Bulls & & & & & & \\
LN & 1 & 0 & 0 & 0 & 0 & 0 \\
GP & 2 & 3 & 0 & 0 & 0 & 7 \\
SEL & 0 & 2 & 35 & 0 & 8 & 13 \\
LMNP & 0 & 2 & 0 & 94 & 0 & 0 \\
MR & 0 & 2 & 11 & 2 & 51 & 22 \\
TNP & 1 & 1 & 8 & 0 & 2 & 228 \\
\hline
\end{tabular}

longest observed one-way seasonal movement $(133.1 \mathrm{~km})$ was an adult male first captured in the Gelai Plains in 2006, then recaptured twice in northern and central Tarangire National Park in 2007, which implies a round-trip migration of c. 300 $\mathrm{km}$. Longer movements (between Tarangire National Park and Lake Natron) were observed across non-consecutive years. Despite more female recaptures than males (650 vs 495 ), both sexes had similar patterns of movement. Female and male median movement lengths between consecutive captures were 7.2 and $5.8 \mathrm{~km}$ per individual, respectively, with 56.0 and $56.2 \%$ of their movement distance occurring outside the three protected areas. Because recapture probabilities were unequal across time and location (i.e. photo recaptures reflected sampling intensity and not movement probabilities) we could not compare the degree of connectivity among different sampling areas. Nonetheless, we observed few recaptures between the two most intensively sampled sites, Tarangire and Lake Manyara National Parks, suggesting these populations do not substantially mix in the dry season, although they have partially overlapping wet season ranges.

\section{GPS collars}

For the two adult wildebeest (male and female) captured and radio-collared on Manyara Ranch we collected relocation data for 14 (female) and 75 (male) days before collar failure. Both individuals used similar routes and passed through the Esilalei corridor on their way north (male and female) and south (female only). The female migrated north of Manyara Ranch to Engaruka village and returned to the Ranch along a similar path between 17 and 22 October (Fig. 2c). The male moved to the Tarangire National Park boundary immediately after its collar was deployed then back to Manyara Ranch for several weeks before migrating north to the Gelai Plains on 9 November, covering a distance of $79.2 \mathrm{~km}$ in 40 hours (Fig. 2c).

\section{Bottlenecks}

Three prominent bottlenecks were evident along the migratory pathway (Figs $1 \&$ \& $)$. In the south the Kwakuchinja bottleneck between Tarangire National Park and Manyara Ranch was c. $1 \mathrm{~km}$ wide at its narrowest point and several $\mathrm{km}$ long, crossing the paved Dodoma road. The Kwakuchinja area supports migration of the Tarangire National Park population to the north and west and allows exchange between the resident Lake Manyara National Park and migratory Tarangire National Park populations. This exchange may facilitate demographic rescue of the Lake Manyara National Park population, as it did in the 1960 s after a period of high lake levels (Prins \& DouglasHamilton, 1990). Dense agriculture and human settlements occur on either side of this bottleneck, and the area currently lacks any formal protection.

The second significant bottleneck, locally known as the Esilalei corridor, is located along the south-western corner of Losimanguri Mountain, where wildlife and livestock move from Manyara Ranch and Lake Manyara National Park to the grasslands east of Selela village and areas further north (Figs 1 \& 2). Both collared wildebeest used this area on their way to and from Manyara Ranch. In addition to crossing a major two-lane paved highway, the migration route passes between the steep slopes of Losimanguri Mountain to the east and rapidly expanding settlements of Mto wa Mbu (Yanda \& Madulu, 2003) to the west. At its narrowest, the bottleneck of open grassland-savannah habitat is c. $800-1,500 \mathrm{~m}$ wide between patches of cultivated land immediately north-west of Manyara Ranch.

Finally, we observed a narrow area along the migration that connects the extensive Gelai Plains and the grasslands and water sources near Lake Natron, here called the Ol Doinyo Lengai bottleneck because of its proximity to the volcano. The bottleneck is situated at the bottom of the steep and rocky slopes of Ol Doinyo Lengai and Gelai mountains and is c. $2 \mathrm{~km}$ wide and $12 \mathrm{~km}$ long (Figs 1 \& 2). Although the aridity of these plains makes them unsuitable for farming (Table 1) a gravel road runs parallel to the migration route in the bottleneck.

\section{Discussion}

Sustaining viable wide-ranging large mammal populations within human-dominated landscapes remains a substantial 
conservation challenge (Newmark, 2008). Although the largest number of extant ungulate migrations occur in Africa (Harris et al., 2009), many of these populations have declined following the loss of migratory routes (Bolger et al., 2008) and most remaining migrations occur within protected areas. Our photographic capture-recapture data demonstrate that wildebeest continue to use migratory routes between Tarangire and Lake Manyara National Parks and the shoreline of Lake Natron, a straight-line distance of $>130 \mathrm{~km}$. The route from Tarangire National Park to Lake Natron passes at least three narrow bottlenecks (0.7-2.0 km wide): Kwakuchinja, Esilalei and Ol Doinyo Lengai, where dense human settlement and steep, rocky topography constrain the set of potential routes (Fig. 1). To our knowledge there are currently no formal policies in place to maintain wildlife connectivity through any of these bottlenecks, despite numerous current and proposed threats to these areas. The small size of these areas makes them particularly vulnerable to land-use changes and also makes them relatively easy to protect compared to other portions of the migratory range.

Given the difficulty of conserving long-distance migrations outside protected areas (Harris et al., 2009), it is important to examine the consequences if connectivity in the Tarangire-Manyara Ecosystem should be further eroded or lost. Firstly, populations using the Simanjiro and Northern Plains appear to be largely distinct despite mixing within the same area and with herds in Tarangire National Park during the dry season (Morrison \& Bolger, 2012). Across years, wildebeest exhibit high fidelity to their wet season ranges: $82-100 \%$ return to the same range each year. Even if some have the capacity to switch ranges, the Simanjiro Plains are greatly affected by agricultural development and human settlement (Sachedina, 2008; Voeten et al., 2010) and therefore may not be a suitable alternative should the northern migration be lost. Recently, portions of rangeland in Simanjiro have been protected from agricultural development through conservation easement agreements with local communities (Nelson et al., 2010), potentially mitigating some of these effects.

Secondly, loss of connectivity in the north could cause wildebeest to become more sedentary. There is no permanent water supply in most of the Northern Plains and therefore wildebeest cannot reside there year round. Tarangire National Park contains permanent water but may have forage of insufficient crude protein and phosphorus concentrations during the wet season to support a sedentary wildebeest population (Voeten et al., 2010). The Northern Plains, in contrast, have younger volcanic soils than Tarangire National Park because of their proximity to the active Ol Doinyo Lengai volcano (Fig. 1), which emits natrocarbonatite ash rich in calcium, sodium and potassium (Bailey, 1993). These soil conditions and the area's relatively low rainfall (Table 1) generally favour the growth of highly digestible forage with high nutrient concentrations (nitrogen and calcium) during the rainy season (McNaughton, 1990). Thus, the Northern Plains are likely to be a crucial source of high-quality forage for migratory ungulates during the wet season, similar to the short grass plains in the Serengeti-Mara Ecosystem.

Past examples suggest that the loss of seasonal ranges in migratory systems typically lead to population declines or collapses (Fynn \& Bonyongo, 2010). For example, in Etosha and Kruger National Parks in southern Africa wildebeest declined 85 and $87 \%$, respectively, following the fencing of these parks (Whyte \& Joubert, 1988; Berry, 1997). Similarly, in the Kalahari, wildebeest declined by tens of thousands of animals in the 1960 s following the construction of wildlife-proof veterinary fences, although drought may have compounded these effects (Spinage, 1992). In southern Kenya wildebeest have suffered widespread declines following the fragmentation of historical ranges (Estes \& East, 2009). Population models suggest that sedentarization of the Serengeti wildebeest population as a result of an impermeable migration barrier (e.g. a fenced road) and subsequent loss of access to high-quality forage could reduce abundance by $35-90 \%$ (Holdo et al., 2011). The severity of these population declines is alarming, and highlights the need to identify priority conservation areas in migratory landscapes.

The majority of the eastern white-bearded wildebeest subspecies C. taurinus albojubatus occur in the TarangireManyara Ecosystem. Overall the subspecies has declined by $62-90 \%$ since systematic surveys were first conducted in the 1960 s (Estes \& East, 2009). Given the truncation (Borner, 1985) of many of the Tarangire-Manyara migration routes first described by Lamprey (1964), the extensive northern grasslands, including the grassy shore of Lake Natron, are probably important for the long-term prospects of the population. In addition to an annual human population growth rate of $6.2 \%$ in nearby villages (Yanda \& Madulu, 2003) and substantial illegal hunting (Estes \& East, 2009), the Northern Plains may soon support a paved road running parallel to the migration between Mto wa Mbu and Lake Natron that will serve as a major transportation route between Arusha and western Tanzania. This controversial road (its proposed route passes through the northern Serengeti; Dobson et al., 2010; Holdo et al., 2011) would further constrain the Ol Doinyo Lengai bottleneck. Additional proposed soda ash mining along the shore of Lake Natron and in Engaruka village would probably increase traffic along this road and remove portions of grazing habitat along the lake shore.

Protecting migration bottlenecks in Tarangire and elsewhere is difficult because animals only occur intermittently at any given location during their annual migration cycle. This diminishes the potential for conservation measures tied to year-round photographic tourism or 
sport hunting, and it complicates anti-poaching measures. Villages near Kwa Kuchinja have established a locally managed protected area (called a Wildlife Management Area), which restricts agricultural activities and promotes wildlife management and revenue-sharing at the community level (Nelson et al., 2007). Although similar efforts are underway near the Ol Doinyo Lengai bottleneck, none have yet been initiated near the Esilalei bottleneck. Although the spatial restriction and small absolute size of bottlenecks makes them vulnerable to disturbance, these features also make bottlenecks relatively easy to conserve. Conservation efforts aimed at migratory ungulates in the TarangireManyara Ecosystem need to concentrate on protecting the described bottlenecks as an efficient way to maintain the broader integrity of the ecosystem.

\section{Acknowledgements}

We are grateful to Tanzania National Parks, the Tanzania Wildlife Research Institute, the Wildlife Division, the Commission for Science and Technology, and the many villages in the Tarangire-Manyara Ecosystem for permission to conduct our research. We thank the Wildlife Conservation Society Tarangire Elephant Project for funding, as well as Dartmouth College, the Marion and Jasper Whiting Foundation, the Nelson A. Rockefeller Center and NSF grant DBI-0754773. We thank M. Goldman and two anonymous reviewers for helpful suggestions. Dedicated to the memory of R. Godson Mollel, whose energy and enthusiasm were instrumental to this project.

\section{References}

B Ailey, D.K. (1993) Carbonate magmas. Journal of the Geological Society, 150, 637-651.

Berger, J., Cain, S.L. \& Berger, K.M. (2006) Connecting the dots: an invariant migration corridor links the Holocene to the present. Biology Letters, 2, 528-531.

Berry, H.H. (1997) Aspects of wildebeest Connochaetes taurinus ecology in the Etosha National Park-a synthesis for future management. Madoqua, 20, 137-148.

Bolger, D.T., Morrison, T.A., Vance, B., Lee, D. \& Farid, H. (2012) Development and application of a computer-assisted system for photographic mark-recapture analysis. Methods in Ecology and Evolution, 3, 813-822.

Bolger, D.T., Newmark, W.D., Morrison, T.A. \& Doak, D.F. (2008) The need for integrative approaches to understand and conserve migratory ungulates. Ecology Letters, 11, 63-77.

Borner, M. (1985) The increasing isolation of Tarangire National Park. Oryx, 19, 91-96.

Casebeer, R.L. \& Koss, G.G. (1970) Food habits of wildebeest, zebra, hartebeest and cattle in Kenya Masailand. African Journal of Ecology, 8, 25-36.

Crooks, K.R. \& Sanjayan, M.A. (2006) Connectivity Conservation. Cambridge University Press, Cambridge, UK.
Dobson, A.P., Borner, M., Sinclair, A.R.E., Hudson, P.J., Anderson, T.M., Bigurube, G. et al. (2010) Road must not divide the Serengeti. Nature, 467, 272-273.

Estes, R. \& East, R. (2009) Status of Wildebeest (Connochaetes taurinus) in the Wild, 1967-2005. Working Paper No. 37. Wildlife Conservation Society, New York, USA.

Foley, C.A.H. \& FAust, L.J. (2010) Rapid population growth in an elephant Loxodonta africana population recovering from poaching in Tarangire National Park, Tanzania. Oryx, 44, 205.

FAO (Food and Agriculture Organization) (1983) Soils and Physiography Database. Dar es Salaam, Tanzania.

Fryxell, J.M. \& Sinclair, A.R.E. (1988) Causes and consequences of migration by large herbivores. Trends in Ecology and Evolution, 3, 237-241.

Fynn, R.W.S. \& Bonyongo, M.C. (2010) Functional conservation areas and the future of Africa's wildlife. African Journal of Ecology, $49,175-188$.

Georgiadis, N. (1995) Population structure of wildebeest: implications for conservation. In Serengeti II: Dynamics, Management and Conservation of an Ecosystem (eds A.R.E. Sinclair \& P. Arcese), pp. 473-484. University of Chicago Press, Chicago, USA.

Goldman, M. (2003) Partitioned nature, privileged knowledge: community-based conservation in Tanzania. Development and Change, 34, 833-862.

Harris, G., Thirgood, S., Hopcraft, J.G.C., Cromsight, J. \& BERGER, J. (2009) Global decline in aggregated migrations of large terrestrial mammals. Endangered Species Research, 7, 55-76.

Hebblewhite, M. \& Merrill, E.H. (2007) Multiscale wolf predation risk for elk: does migration reduce risk? Oecologia, 152, 377-387.

Hijmans, R.J., Cameron, S.E., Parra, J.L., Jones, P.G. \& Jarvis, A. (2005) Very high resolution interpolated climate surfaces for global land areas. International Journal of Climatology, 25, 1965-1978.

Holdo, R.M., Fryxell, J.M., Sinclair, A.R.E., Dobson, A. \& Holt, R.D. (2011) Predicted impacts of barriers to migration on the Serengeti wildebeest population. PLOS ONE, 6, 1-7.

Holdo, R.M., Holt, R.D. \& Fryxell, J.M. (2009) Grazers, browsers, and fire influence the extent and spatial pattern of tree cover in the Serengeti. Ecological Applications, 19, 95-109.

Hopcraft, J.G.C., Olff, H. \& Sinclair, A.R.E. (2010) Herbivores, resources and risks: alternating regulation along primary environmental gradients in savannas. Trends in Ecology and Evolution, 25, 119-128.

LAMPREY, H.F. (1964) Estimation of the large mammal densities, biomass and energy exchange in the Tarangire game reserve and the Masai Steppe in Tanganyika. East African Journal of Wildlife, 2, $1-46$.

McNaughton, M.M. (1990) Mineral nutrition and seasonal movements of African migratory ungulates. Nature, 345, 613-615.

MorRison, T.A. \& BOLGER, D.T. (2012) Wet season range fidelity in a tropical migratory ungulate. Journal of Animal Ecology, 81, 543-552.

Morrison, T.A., Yoshizaki, J., Nichols, J.D. \& Bolger, D.T. (2011) Estimating survival in photographic capture-recapture studies: overcoming misidentification error. Methods in Ecology and Evolution, 2, 454-463.

Nelson, F., Foley, C., Foley, L.S., Leposo, A., Loure, E., Peterson, D. et al. (2010) Payments for ecosystem services as a framework for community-based conservation in Northern Tanzania. Conservation Biology, 24, 78-85.

Nelson, F., Nshala, R. \& Rodgers, W.A. (2007) The evolution and reform of Tanzanian wildlife management. Conservation and Society, 5, 232-261.

Newmark, W.D. (2008) Isolation of African protected areas. Frontiers in Ecology and the Environment, 6, 321-328. 
Ogutu, J.O., Piepho, H.P., Reid, R.S., Rainy, M.E., Kruska, R.L., WORDEN, J.S. et al. (2010) Large herbivore responses to water and settlements in savannas. Ecological Monographs, 80, 241-266.

PrINS, H.H.T. (1996) Ecology and Behaviour of the African Buffalo: Social Inequality and Decision Making. Chapman \& Hall, London, UK.

Prins, H.H.T. \& Douglas-Hamilton, I. (1990) Stability in a multispecies assemblage of large herbivores in East Africa. Oecologia, 83 , 392-400.

Sachedina, H. (2008) Wildlife is our oil: conservation, livelihoods and NGOs in the Tarangire Ecosystem, Tanzania. $\mathrm{PhD}$ thesis. University of Oxford, Oxford, UK.

Sawyer, H., Kauffman, M.J., Middleton, A., Morrison, T.A., Nielsen, R. \& Wyckoff, T. (2013) A framework for understanding semi-permeable barrier effects on migratory ungulates. Journal of Applied Ecology, 50, 68-78.

Sawyer, H., Kauffman, M.J., Nielson, R.M. \& Horne, J.S. (2009) Identifying and prioritizing ungulate migration routes for landscape-level conservation. Ecological Applications, 19, 2016-2025.

Spinage, C.A. (1992) The decline of the Kalahari wildebeest. Oryx, 26, 147-150.

TAWIRI (Tanzania Wildlife Research Institute) (2001) Aerial Census in the Tarangire Ecosystem. Conservation Information and Monitoring Unit, Arusha, Tanzania.

TCP (Tarangire Conservation Project) (1998) Analysis of Migratory Movements of Large Mammals and their Interactions with Human Activities in the Tarangire Area in Tanzania as a Contribution to a Conservation and Sustainable Development Strategy. Final Report. Oikos, Arusha, Tanzania.
Thirgood, S., Mosser, A., Tham, S., Hopcraft, G., Mwangomo, E., Mlengeya, T. et al. (2004) Can parks protect migratory ungulates? The case of the Serengeti wildebeest. Animal Conservation, 7, 113-120.

Voeten, M.M., Van De Vijver, C., OlfF, H. \&

Van Langevelde, F. (2010) Possible causes of decreasing migratory ungulate populations in an East African savannah after restrictions in their seasonal movements. African Journal of Ecology, $48,169-179$.

Whyte, I.J. \& Joubert, S.C.J. (1988) Blue wildebeest population trends in the Kruger National Park and the effects of fencing. South African Journal of Wildlife Research, 18, $78-87$.

WILD-ID (2013) Http://www.dartmouth.edu/ envs/faculty/bolger. html [accessed 18 October 2013].

Yand A, P.Z. \& Madulu, N.F. (2003) Natural Resources Use Patterns and Poverty Alleviation Strategies in the Highlands and Lowlands of Karatu and Monduli Districts: a Study on Linkages and Environmental Implications. University of Dar es Salaam, Dar es Salaam, Tanzania.

\section{Biographical sketches}

TOM MORRISON is interested in the population ecology of wideranging mammals, particularly in East Africa. The majority of his research aims to support management and conservation decisionmaking. DOU G Bolger studies conservation and population biology of ungulates in Africa and his teaching focuses on the intersection between environment and development. 